International JOURNAL OF MULTidisciplinary RESEARCH AND ANALysis

ISSN(print): 2643-9840, ISSN(online): 2643-9875

Volume 05 Issue 02 February 2022

DOI: 10.47191/ijmra/v5-i2-23, Impact Factor: 6.072

Page No. 391-398

\title{
Clinical \& Biochemical Profile of Covid 19 Patients With and Without Co Morbidities
}

\author{
Dr. R. Shivasuvramaniyam M.D. ${ }^{1}$, Dr. Minakshi M.D. ${ }^{2}$ \\ ${ }^{1}$ Professor\& Head Department of Medical Biochemistry, Jaipur National University Jaipur Rajasthan India 302017 \\ ${ }^{2}$ Associate Professor, Magathama Gandhi Medical College Jaipur, Rajasthan
}

\begin{abstract}
The pandemic outbreak of noval corona virus disease (covid19) was initially noticed in a seafood market in wuhan city in china in mid-December, 2019, has spreaded to 215 countries worldwide. 2020 january7th and was temporally named $2019 \mathrm{n}$ co.v

Corona virus belongs to a large family of virus that causes illness ranging from the common cold to more severe disease, A noval corona virus is a new strain that has not been previously identified in humans on January $30^{\text {th }} 2020$ declared the noval corona virus outbreak of public health emergency of international concern (PHEIC). At that time there was 98 cases and no death in 18 countries outside china.

The official name covid-19 and SARS -COV2 was issued by the WHO on $11^{\text {th }}$ February 2020 Viruses are named based on their genetic structure to facilitate the development of diagnostic test, Vaccine and medium. Virologist and the wider scientific committee do this work, so virus is are named by the international committee on taxonomy of viruses.

A recent review of the survival of human corona virus on surface found large variability ranging from 2 hours to 9 days. The survival time depends on number of factors, including the type of surface, temperature, relative humidity and specific strain of viruses.

March $11^{\text {th }} 2020$, the rapid increase in the number of cases outside china. 118000 cases had been reported in 114 countries and 4291 deaths had been reported.

Middle of the March 2020 corona out break could be characterized by "Pandemic" reporting over 40108 globally confirmed cases. As of $28^{\text {th }}$ April $2020,63 \%$ of global mortality from the virus.

The impact of the dieses on the world has been staggering both from public health and economic perspective. We evaluated whether prior or active corona virus infection influenced hematological, Biochemical and Clinical parameters of the such patients. But active corona fever resulted in higher hospitalization rate. Our data support the nation that SARS- COV-2 and co morbidity weather affects an important percentage of covid 19 pateints and leads to worse parameters, requiring greater attention from health authorities.
\end{abstract}

KEYWORDS: Covid, SARS-CO-2 Infection, SARS -CO-2 Infection with Comorbidities, hematological, Biochemical, Markers, ARDS, acute respiratory distress syndrome; SARS-CO2, corona virus disease CRP- C reactive protein; ICU, intensive care unit; PCT, procalcitonin.

\section{INTRODUCTION}

The severe acute respiratory syndrome corona virus-2 (SARS-CO-V-2) quickly spread to several countries, infecting millions of people worldwide. Thereafter, the number of infected individuals from all countries continued to grow daily reaching day by day expressive figures.

Most (SARS-CO-V-2) infective individuals are asymptomatic on present non-specific, flu-like symptoms, such as fever, headache, fatigue and dry cough. However, clinically conditions can rapidly progress to sever pneumonia and ultimately death, mainly in patients who present comorbidity such as obesity, type II DM, CVS, neurological disorders. Although research is happing at over whelming speed to biochemical, hematology data and day to day investigations for effective treatment.

The impact of this disease on the world has been steggering, both from the public health and economic perspectives. A worse scenario has been witnessed in South America. Specially in Brazil, Ecuador, Argentina, and Peru. Recently highest number of cases of covid 19 in the region. It has been hypothesized that such countries possible experienced an aggravated covid 19 pandemic due 


\section{Clinical \& Biochemical Profile of Covid 19 Patients With and Without Co Morbidities}

to socioeconomic and health factors. Co- morbidity infection being mostly reported in endemic and various non- endemic countries.

Corona fever is an endemic disease, by continuous vector transmission in several tropical areas around the world. The covid-19 pandemic brought additional uncertainty to countries that already needed to deal with Co-morbidity of obesity, MI, CVS, Type II DM. The circulation of both viruses represents a major challenge for hospitals that will have to face difficulties in determining to biochemical parameters to diagnosis due to overlapping symptoms between Co-morbidity and covid-19. The consequences of covid-19 and Co-morbidity disease misdiagnosis are relevant and may include ineffective patient management. The clinical consequences of SARS-CO-V-2 and Co-morbidity disease infection are still unknown. Justifying investigations in the theme and dose vigilance by health authorities. Data regarding patients hematological and biochemical parameters, as well as clinical outcomes, were collected and analyzed.

We detected that a significant percentage of Covid 19 patients presented by virus infection did not significantly influence clinical and laboratorial parameters, active SARS-CO-V-2 was associated with more frequent detectable lung alterations and hospitalization, our data may provide important information to health authorities to improve the identification and the management of these patients.

\section{AIMS AND OBJECTIVES}

We are planned of 300 patients aged 18 + years who were admitted to the hospital emergency department and Covid-19 ward, presenting 75 patients of Covid-19 and 25 patients of Covid 19 Co morbidity-obesity, Type II DM, COPD, RENAL FAILURE MYOCARDIAL INFRACTION CHIRROSIS OF LIVER symptoms and performed the patient sample to analysis for strategic management.

The medical history carefully examined the patients and then filled their medical record with proforma data regarding and clinical history of fever, cough, dyspnoea, fatigue, headache, sorethroat, chest pain, diarrhea, vomiting, anosmia and in appetite. Patient clinical follow-up was assesed on medical record and was to determine major clinical outcome such as investigations of biochemical parameters and hospitalization.

\section{ANALYTICAL PARAMETERS:-}

1. Complete urine analysis.

2. Complete Blood Hematological analysis.

3. Complete Blood Biochemical analysis.

4. Covid 19, Antigen, Antibody Rapid test.

5. Throat Swab - RT PCR.

6. CRP, Ferritin, D-dimer, IL6.

7. Electrophoresis-Hemoglobin

$$
\begin{aligned}
& \text { - Protein } \\
& \text { - Lipid } \\
& \text { - CSF }
\end{aligned}
$$
8. USG - Abdomen.
9. ECG, ECHO. - Color Doppler
10. HRCT - Thorax
11. CT - Brain
12. MRI - Brain

\section{MATERIALS AND METHODS}

The Study was performed with a convenience sample of patient assessed in JNU Hospital and study was to be approve by Ethics committee of JNUIMSRC.

Covid-19 diagnosis was confirmed by Reverse transcription-polymerase chain reaction (RT-PCR) assay of nasopharyngeal swab sample. Viral RNA was extracted using the high pure viral nucleic acid version by the step are plus reactive PCR systems methods. Hematology blood sample were used to analyze by flow cytometry.

Biochemical samples were used to analyze by fully auto analyzer diagnostic equipment. Serology test were carried out the methods based on indirect ELISA technique, immune plates are coated with a mixture of purified viral antigen and probe using the patient serum. And all Radiological investigations by highly modular technique of the Radiological Equipments 


\section{Clinical \& Biochemical Profile of Covid 19 Patients With and Without Co Morbidities}

Seventy five covid 19 survivors' twenty five co-morbidity non survivors and biochemical markers are studied and have been reported this is descriptive study and the comparisons between the two are analyzed.

\section{INCLUSION CRITERIA}

Patients with a history of fever more than one week with cough, dysponea, fatigue, sore throat, chest pain, diarrhea, vomiting, anosmic, aguesia and inappetite. Patient clinical follow-up as assesed to medical records.

Blood samples were used to analyze hematological parameters by flow cytometry. Serum samples were characterized according to the liver profile, renal profile, lipid profile, diabetic profile, coagulation profile, cardiac markers, CRP, D- dimer, ferritin, ABG parameters, electrolyte analysis and urine complete analysis by equipment of Randox Imola Autoanalyzer and used high resolution computed tomography (HRCT) was used to asses patient lung condition and RT-PCR to identify corona virus infection and rapid antibody test for the scoring to corona virus infection.

All statistical analysis were performed quantitative data were submitted to analysis of frequently using procedure with subsequent chi-square analysis at $95 \%$ confidence interval to assess whether clinical parameters would significantly varies between Covid-19 co morbidity infection and Covid-19 past fever positive. Quantitative data were normality test using and then submitted to detect difference between Covid-19 co morbidity infection and Covid-19 past fever group patient.

All subjects were evaluated and selected by detailed medical history and physical examination, each subject gave informed consent and the study was approved by institutional ethical and research committee.

\section{PROFORMA STATUS}

JNU University Institute of Medical Science and Research Center (Jaipur, Rajasthan)

\section{DEPARTMENT OF BIOCHEMISTRY}

Research topic: A study to utility for Biochemical Parameters in Covid 19 Patients versuses COVID-19 comorbidity Investigator name: ., Dr. Shivasubramaniam M.D Dr.Minakshi M.D

1. Patient name/detail: Total 100 Patients

2. Age: $25-70$ yrs old Sex: Male-40 Patients Female-60 Patients

3. Patient Id: Hospital Registration OP/IPD NUMBER

4. Weight: $32 \mathrm{~kg}$ - up to $90 \mathrm{~kg}$ various

5. Height: $132 \mathrm{~cm}$. to $180 \mathrm{~cm}$. various

6. BMI: 20 to up to 45 various

7. Religion: Hindu /Muslim/Sikh/Christion/Others

8. Area: Urban 60 Patients. Rural: 40 Patients

9. Tribal 10 Patients Non tribal: 90 Patients

10. Deit: Vegetarian 60 Patients Non Vegetarian: 40 Patients

11. Smokers 80 Patients Non Smokers: 40 Pateints

12. Chewing habit: 80 Patients

13. Alcoholism: 40 Patients Non Alcoholism: 35 Patients

14. Medical History: Fever, Cough, Cold, Tiredness, Breathlessness, with Hypertension, Diabetics, Renal Failure, Alcoholic cirrhosis, Acid peptic disorders 60 Patients in Covid-19. Covid-19 only 40 Patients

15. Patient Medical Co-Morbidity Disease History. 25 Patients 


\section{Clinical \& Biochemical Profile of Covid 19 Patients With and Without Co Morbidities}

\section{STUDY FLOW DIAGRAM}
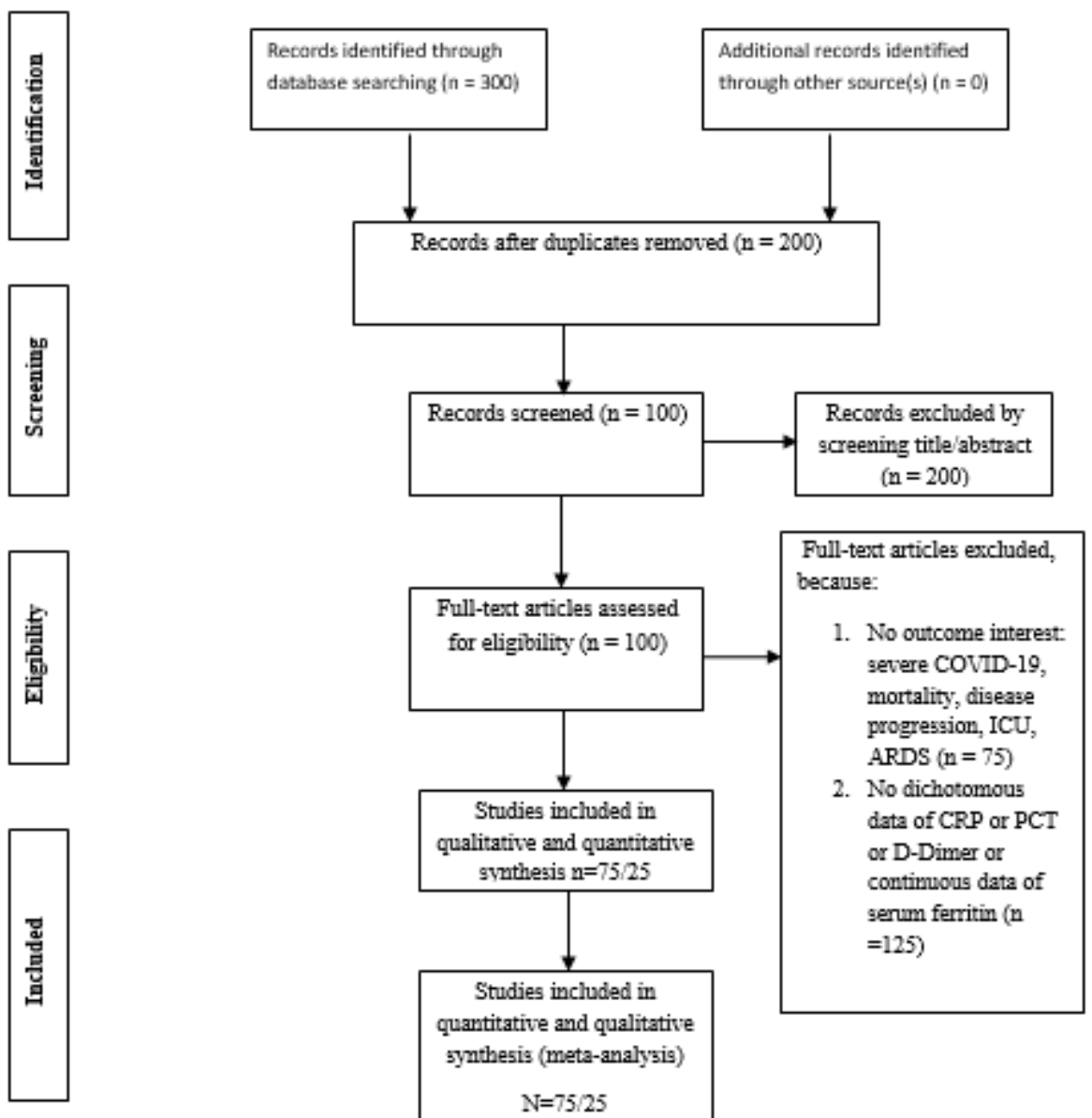

ARDS, acute respiratory distress syndrome; COVID-19, corona virus disease - CRP, C-reactive protein; ICU, intensive care unit;

PCT, procalcitonin.

\section{RESULTS}

Table to describe the hematological and biochemical profile in COVID -19 and Co morbidity COVID -19:

\begin{tabular}{|l|l|l|l|}
\hline Markers & COVID -19 & Co Morbidity COVID -19 & Sig \\
\hline WBC total count $\left(10^{9} / \mathrm{L}\right)$ & $4.8 \pm 3.7$ & $8.9 \pm 6.0$ & Not Sig \\
\hline Neutrophils count $\left(10^{9} / \mathrm{L}\right)$ & $5.9 \pm 1.5$ & $8.4 \pm 2.1$ & $<0.001$ Sig \\
\hline Lymphocytes count $\left(10^{9} / \mathrm{L}\right)$ & $2.4 \pm 1.4$ & $1.3 \pm 0.5$ & Not Sig \\
\hline Platelet count. $\left(10^{9} / \mathrm{L}\right)$ & $184.07 \pm 38.15$ & $101.58 \pm 70.27$ & $<0.001$ Sig \\
\hline Hb $\%$ & $12.81 \pm 1.72$ & $10.27 \pm 1.29$ & Not Sig \\
\hline Serum Sodium, mmol/L & $138.21 \pm 2.38$ & $140.35 \pm 7.39$ & Not Sig \\
\hline Serum Potassium, mmol/L & $4.12 \pm 0.13$ & $4.41 \pm 0.92$ & Not Sig \\
\hline Serum Chloride, $\mathrm{mmol} / \mathrm{L}$ & $96.71 \pm 6.18$ & $94.49 \pm 7.8$ & Not Sig \\
\hline AST U/L & $68.38 \pm 34.29$ & $90.8 \pm 114.98$ & Not Sig \\
\hline ALT U/L & $49.82 \pm 38.92$ & $121.38 \pm 187.48$ & Not Sig \\
\hline LDH U/L & $620.28 \pm 318.09$ & $1216.16 \pm 1129.29$ & $<0.001$ Sig \\
\hline Direct billrubin, $\mathrm{mmol} / \mathrm{L}$ & $0.61 \pm 1.23$ & $0.79 \pm 1.12$ & Not Sig \\
\hline InDirect billrubin, $\mathrm{mmol} / \mathrm{L}$ & $0.41 \pm 1.17$ & $0.75 \pm 1.39$ & Not Sig \\
\hline TBIC, $\mathrm{mmol} / \mathrm{L}$ & $1.11 \pm 1.22$ & $1.45 \pm 1.92$ & Not Sig \\
\hline CRP, mg/L & $39.29 \pm 57.12$ & $116.26 \pm 91.9$ & $<0.001$ Sig \\
\hline D-dimer, $\mathrm{ng} / \mathrm{mL}$ & $682.00 \pm 114.19$ & $892.13 \pm 412.38$ & $<0.001$ Sig \\
\hline Ferritin $\mathrm{ng} / \mathrm{mL}$ & $249.91 \pm 38.15$ & $1006.16 \pm 112.39$ & $<0.001$ Sig \\
\hline Procalcitonin & $3.92 \pm 6.99$ & $2.90 \pm 10.22$ & $<0.01$ Sig. \\
\hline IL-6 & $42 \pm 70$ & $68 \pm 1.10$ & $<0.01$ Sig. \\
\hline SpO2 on admission & $93.82 \pm 6.39$ & $86.28 \pm 6.0$ & Not Sig \\
\hline
\end{tabular}




\section{Clinical \& Biochemical Profile of Covid 19 Patients With and Without Co Morbidities}

Graph 1\& 2: to describe the biochemical markers in COVID-19 and Co morbidity COVID-19.

$\square$ Red-COVID-19 Co morbidity

$\square$ Green - COVID -19
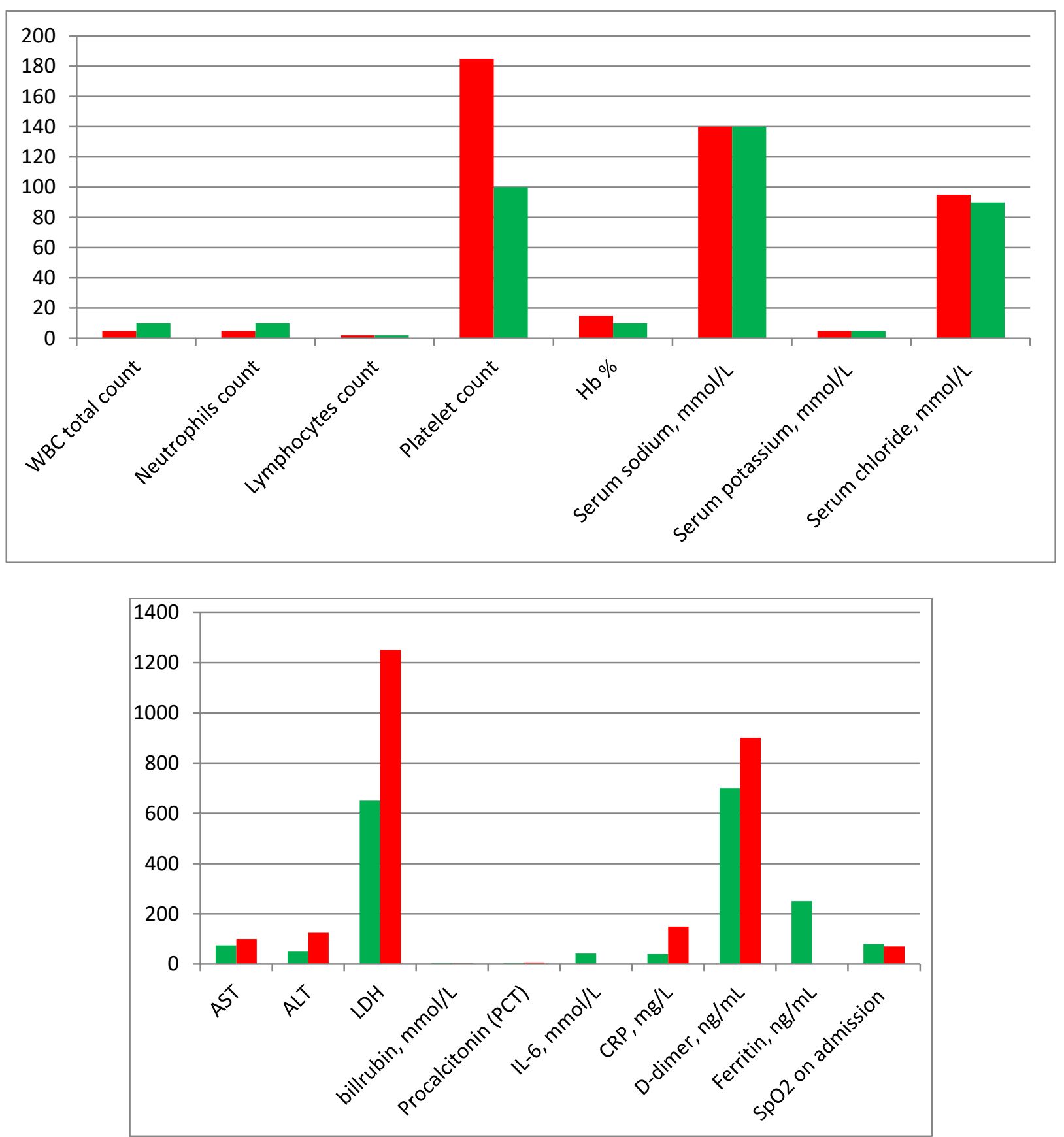

\section{DISCUSSION}

This disease has a peculiar natural course. This starts off with mild symptoms and then suddenly the signs and symptoms blows out of proportion and eventually is very hard to treat. So identification of the stage is very important so that the treating doctor gets a chance to effectively treat the patient. ${ }^{8}$ Some of the reports have already marked the importance of the hematological and biochemical markers to identify the prognosis of the disease ${ }^{4,9}$ No such study has been done in the present population and this is one such sincere effort, some study has also reported the importance of inflammatory markers in the patients, C-reactive protein (CRP) is one such, others like erythrocyte sedimentation rate (ESR), and interleukin-6 are also extensively studied. ${ }^{3}$ Likewise, another work reported lymphocytopenia, high blood sugar, gamma-glutamyl transferees (GGT), high lactate dehydrogenises (LDH) in more COVID-19 patients. ${ }^{10}$ Further, laboratory findings of 77 COVID-19 deaths and 150 COVID-19 patients also demonstrated an increase in urea, cardiac troponin, creatine kinase, D-dimer, C-reactive protein (CRP), lactate dehydrogenises (LDH), IL-6, and lower level of lactic acid levels and lymphocytes. ${ }^{11,12}$ Analysis of 100 cases of COVID-19 revealed a higher level of C-reactive protein, D-dimer, lactate dehydrogenises, serum amyloid, and lower level of albumin are directly associated with developing a 


\section{Clinical \& Biochemical Profile of Covid 19 Patients With and Without Co Morbidities}

critical illness. ${ }^{9}$ The hematological and biochemical markers have been studied and this study successfully proves the difference. This can be used as a prognostic tool. Majority of the study has been done in the east and none of them in this region. The pandemic is still not over and this study is one novel effort to find the difference so as to help the practicing physician to diagnose the severity earlier and be helpful in the treatment of the disease. This meta-analysis showed that elevated serum CRP,PCT , Ddimer, and serum ferritin levels were associated with an increased composite poor outcome that comprise mortality, severe COVID-19 WARDS, and the need for ICU care in patients with COVID-19. The effect estimate was not significance modified by gender, age, cardiovascular disease, diabetes, and COPD.

In the systemic hyper inflammation phase of COVID-19 proposed there significant elevation of inflammatory cytokines and biomarkers, such as interleukin (IL)-2, VIL-6 granulocyte-colony stimulating factor, macrophage inflammatory protein 1- $\alpha$, tumor necrosis face (TNF- $\alpha$ ), CRP, ferritin, PCT, and D-dimer. This stage consists of the most severe manifestation cytokine storm, in which excessive hyper inflammation may lead to cardiopulmonary collapse ar. Multi-organ failure. $\frac{35,36}{3}$

CRP is an acute phase inflammatory protein produced by the liver that may be elevated in several conditions, such as inflammation, cardiovascular disease, and infection. $\frac{37}{}$ In our meta- analysis studies, an elevated CRP was associated with severe COVID-19, the need for ICU care, but not mortality. Al though there is no general agreement on a cutoff point to determining the severity 0 COVID-19, the majority of the studies used a $\geq 10 \mathrm{mg} / \mathrm{L}$ cutoff. Our SROC analysis showed the diagnostic value of serum CRP> $10 \mathrm{mg} / \mathrm{L}$ for a composite poor outcome in COVID-19 (51\% sensitivity, 88\% specificity, an LR +of 4.1 and an LR - of 0.5). Previous studies that attempted to predict mortality in sepsis by the presence of an elevated serum CRP were inconclusive. A study showed that an elevated serum CRP level was associated with a 30-day mortality rate, ${ }^{38}$ while o studies showed otherwise. $\frac{39-41}{1}$ These inconsistencies might be caused by the different cutoff value used. In the study by Koozi et al., the cutoff value for an elevated serum CRP was $>1000 \mathrm{mg} / \mathrm{L}$, while in the study by Ryoo et al., the cutoff point of $\geq 140 \mathrm{mg} / \mathrm{L}$ was used. $\frac{41}{1}$ Liu et al. proposed cutoff value of $\geq 41.8 \mathrm{mg} / \mathrm{L}$ to predict severe COVID-19. $\underline{42}$ In our analysis, the cutoff values of serum CRP varied widely, with the lowest and highest values being $>3 \mathrm{mg} / \mathrm{L}$ and $>100 \mathrm{mg} / \mathrm{L}$, respective these findings reflected the paramount need for pursuing the optional serum CRP cut off value for COVID-19 Prognostication. The time period for serum CRP measurement was critical in light

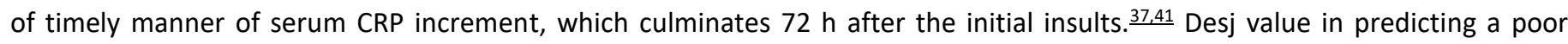
outcome in COVID-19, it should we noted that various factors could a serum CRP levels, including age, gender, smoking status, weight, lipid levels, blood pressure, are injury. $\frac{37}{}$ These factors should be taken into account while interpreting the serum CRP level. In addition, recent evidence has shown that serum CRP level could also be used in monitoring the progression and improvement of patients with COVID-19. $\underline{43}$

A peptide precursor of the hormone calcitonin, PCT, has been widely investigated as a promising biomarker for the initial investigation of a bacterial infection. $\frac{44}{}$ An elevated serum PCT is often in patients with sepsis and septic shock. $\frac{39}{}$ While it is still controversial whether PCT can accurate distinguish bacterial or viral pneumonia,,$\underline{45}$ it was found that PCT-guided therapy in acute respire infections reduces the antibiotic exposure and side effects, and improves the survival rate. $\underline{46}$ Bac infections trigger extrathyroidal synthesis of PCT, which is actively maintained by elevated valu IL-6, IL-1 $\beta$, and TNF- $\alpha$, while viral infections hinder PCT production due to interferon- $\gamma$. $\frac{47}{}$ This explains why serum PCT concentrations remain normal in uncomplicated cases of COVID-

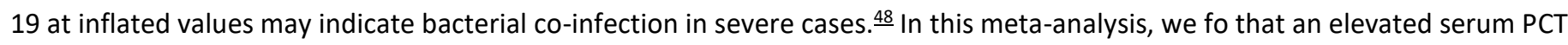
was associated with mortality and severe COVID-19. Our SROC an showed the diagnostic value of serum PCT $\geq 0.5 \mathrm{mg} / \mathrm{L}$ for a composite poor outcome in COVID. (88\% sensitivity, 68\% specificity, LR+2.7 and LR-0.2).

In our study, we also found that an elevated D-dimer was associated with an increased composit outcome, especially mortality and severe COVID-19. This finding supports the hypothesis that s acute respiratory syndrome coronavirus 2 (SARS-CoV-2) infection could induce the dysfunction hemostatic system, leading to a hyper coagulable state, a condition which we commonly encount sepsis. $\frac{49,50}{}$ Recent evidence of lung pathology dissection has shown occlusion and micro-throm formation in pulmonary small vessels of patients critically ill with COVID-19. $\underline{51}$ However, the e of elevated serum D-dimer level is multifactorial and the optimal cutoff value of elevated D-dim patients with COVID-19 remains to be established. It is clear that COVID-19-associated coagul warrants distinct emphasis and special treatment. According to the International Society of Thro and Hemostasis (ISTH) guideline, a markedly elevated serum D-dimer level (which is still poorl defined as a three-to four-fold increase) implies an increased thrombin production. Patients with COVID-19 with markedly elevated D-dimer levels may require hospitalization, despite thesever clinical presentation. $\underline{52}$ In the absence of contraindications, a prophylactic dose of an anticoaguli recommended for all hospitalized patients with COVID-19.

Along with other biomarkers included in this study, we also found that a higher serum ferritin le independently associated with ARDS, mortality, and severe COVID-19. This may lead to the no the presence of secondary hemophagocytic lymphohistiocytosis (sHLH) in COVID-19. $\stackrel{?}{\text { sHLH }}$ i condition of hyperinflammation characterized by a cytokine storm causing fatal multi-organ fail This condition is most commonly triggered by viral infections, $\underline{54}$ which might lead to a hypothe SARS-CoV-2 inducing this 


\section{Clinical \& Biochemical Profile of Covid 19 Patients With and Without Co Morbidities}

hyperinflammatory syndrome. Despite the fact that some authors suj using HScore to identify subgroups of patients that may benefit from immunosuppressive therapy still controversial whether or not this specific condition in severe COVID-19 needs to be treated sHLH. A recent systematic review by Veronese et al. including 542 patients reported conflicting evidence in 4 studies. $\underline{55}$ the authors concluded that the current evidence did not support the rout of corticosteroids in COVID-19, but some findings suggested corticosteroids may reduce the me rate in COVID-19 cases aggravated with ARDS.

\section{CONCLUSIONS}

1) Virus is inside the body detects a virus has never seen and will throw everything against it. The body eliminate the virus but can cause sometimes deadly collateral damage through the body. The study included only people who were unvaccinated and had at least and one risk factor for developing a severe case of Covid-19. The people who are older than 60, obese, Type II DM, CVS, RS, CNS, Abdominal Organ underlying disease, an immunocompromized from another condition like prophylactic vaccine is enough to be hospitalization.

2) Corona virus SARS - COV2 significantly reduces the risk of hospitalization and death in people who take it early in the course of their Covid-19.There was also less likely to die, reported within a month of treatment and now in those who received the medicine. All of the antiviral medicines available today, including remdesivir and the monoclonal antibodies are much more affected against Covid and cut risk of hospitalization and death by up to $85 \%$ but this treatment cost almost higher than normal

3) The research, Study has conducted in numerous place sites around Rajasthan in Jaipur, JNUIMSRC became the results are promising to against corona virus and clinical parameters investigations is improve the identification and the management of the Covid 19 patients. (SARS-CO-V-2)

The hematological and biochemical markers may be used as prognostic markers in COVID-19 and Analysis showed that an elevated serum CRP, PCT, D-dimer IL6, and serum ferritin were associated with a composite poor outcome in patients with COVID-19.

\section{REFERENCES}

1) Li, X. Guan, P. Wu, et al.Early transmission dynamics in wuhan, China, of novel corona virus -infected pneumonia new England journal of medicine, 382 (2020). pp. 1199-207, 10.1056/NEJMoa2001316

2) L. Sheng, X. Wang, N. Tang, et al. clinical characteristics of moderate and severe cases with COVID-19 in Wuhan, China: a retrospective study clinical and Experimental medicine (2020), 10. 1007/s10238-020-00662-z

3) R. Kumar, V. Singh, A. Mohanty, Y. Bahurupi, P.K. Gupta Corona health -care warriors in india: Knowledge, attitude, and practices during COVID-19 outbreak J Educ health promot, 10 (44) (2021), pp. 1-8, 10.4103/jehp.jehp_524_20

4) D. Wang, B. hu, et al. Clinical characteristics of 138 hospitalized patients with 2019 novel corona virus- infected pneumonia in wuhan, China JAMA, 323 (2020), pp. 1061-1069, 10.1001/jama.2020.1585

5) J. -F. Gautier, Y. Ravussin A new symptom of COVID -19: loss of taste and smell obesity (2020), p. 848

6) World Health organization world health organization statement on the second meeting of the international health regulations (2005) Emergency committee regarding the outbreak of novel Corona virus (2019-nCoV) (2020)

7) J. Lu, S. Hu, R. Fan, et al. ACP risk grade: a simple mortality index for patients with confirmed or suspected severe acute respiratory syndrome corona virus -2 disease (COVID -19) During the early stage of outbreak in wuhan medRxiv China (2020) p. 2020.02.20.20025510.

8) J. Liu, Y. Liu, P. Xiang, et al. Neutrophil -to- Lymphocyte ratio predicts severe illness patients with 2019 medRxiv Novel Corona virus in the Early Stage (2020) P.

9) D. Wang, R. Li, J. Wang, et al. Correlation analysis between disease Severity and Clinical and biochemical characteristics of 143 cases of COVID -19 in Wuhan, China: A descriptive study BMC infectious Disease, 20 (2020), p. 519,

10) S. Tian, H. Liu, M. Liao, et al. Analysis of mortality in patients with COVID -19: Clinical and laboratory Parameters Open Forum infectious Disease (2020), p. 7,

11) K. Wang, Z. Qiu, J. Liu, et al. Analysis of the clinical characteristics of 77 COVID -19 deaths. Scientific Reports, 10 (2020), p. 16384,

12) P. R. Martins -Filho, C.S.S. Tavares, V.S. Santos. Factors associated with mortality in patients with COVID -19. A quantitative evidence synthesis of clinical and laboratory data. European journal of internal medicine, 76 (2020), pp. 9799.

13) Liu F, Li L, Xu M, et al. Prognostic value of interleukin-6, C-reactive protein, and procalcito patients with COVID-19. J Clin Virol 2020; 104370. [PMC free article] [PubMed] [Google Scho

14) Li H, Xiang X, Ren H, et al. Serum amyloid A is a biomarker of severe coronavirus disease i poor prognosis. J Infect 2020; 80: 646-655. [PMC free article] [PubMed] [Google Scholar] 


\section{Clinical \& Biochemical Profile of Covid 19 Patients With and Without Co Morbidities}

15) Creamer AW, Kent AE, Albur M. Procalcitonin in respiratory disease: use as a biomarker for diagnosis and guiding antibiotic therapy. Breathe 2019; 15: 296-304. [PMC free article] [PubM [Google Scholar]

16) Kamat IS, Ramachandran V. Eswaran $\mathrm{H}$, et al. Procalcitonin to distinguish viral from bacteri pneumonia: a systematic review and meta-analysis. Clin Infect Dis 2020; 70: 538-542. [PubMex [Google Scholar]

17) Schuetz $P$, Wirz $Y$, Sager $R$, et al. Effect of procalcitonin-guided antibiotic treatment on mort acute respiratory infections: a patient level meta-analysis. Lancet Infect Dis 2018; 18: 95-107. [PubMed] [Google Scholar]

18) Schuetz $P$, Albrich $W$, Mueller B. Procalcitonin for diagnosis of infection and guide to antibi decisions: past, present and future. BMC Med 2011; 9: 107. [PMC free article] [PubMed] [Google Scholar]

19) Lippi G, Plebani M. Procalcitonin in patients with severe coronavirus disease 2019 (COVID meta-analysis. Clin Chim Acta 2020; 505: 190-191. [PMC free article] [PubMed] [Google Scholar]

20) Levi M, van der Poll T. Coagulation and sepsis. Thromb Res 2017; 149: 38-44. [PubMed] [Google Scholar]

21) Lin L, Lu L, Cao W, et al. Hypothesis for potential pathogenesis of SARS-CoV-2 infection-Review of immune changes in patients with viral pneumonia. Emerg Microbes Infect 2020; 1-14 [PMC free article] [PubMed] [Google Scholar]

22) Lue W, Yu H, Gou J, et al. Clinical pathology of critical patient with novel coronavirus pneu (COVID-19). Preprints 2020; 1-18. [Google Scholar]

23) Thachil J, Tang N, Gando S, et al. ISTH interim guidance on recognition and management of coagulopathy in COVID-19. J Thromb Haemost 2020; 1023-1026. [PubMed] [Google Scholar]

24) Karakike E, Giamarellos-Bourboulis EJ. Macrophage activation-like syndrome: a distinct en leading to early death in sepsis. Front Immunol 2019, 10: 55. [PMC free article] [PubMed] [Google Scholar]

25) Ramos-Casals M, Brito-Zerón P, López-Guillermo A, et al. Adult haemophagocytic syndrom Lancet 2014; 383: $1503-1516$. [PubMed] [Google Scholar]

26) Veronese N, Demurtas J, Yang L, et al. Use of corticosteroids in coronavirus disease 2019 pneumonia: a systematic review of the literature. Front Med 2020; 7: 1-6. [PMC free article] [PubMed] [Google Scholar]

27) Pranata R, Lim MA, Huang 1, et al. Hypertension is associated with increased mortality and severity of disease in COVID19 pneumonia: a systematic review, meta-analysis and meta-regre Renin Angiotensin Aldosterone Syst 2020; 1-11. [PMC free article] [PubMed] [Google Scholar]

28) Pranata R, Soeroto AY, Huang I, et al. Effect of chronic obstructive pulmonary disease and smoking on the outcome of COVID-19. Int J Tuberc Lung Dis. Epub ahead of print 28 may 2020 10.5588/ijtld.20.0278. [CrossRef] [Google Scholar]

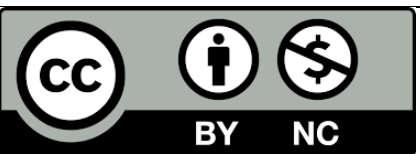

There is an Open Access article, distributed under the term of the Creative Commons Attribution - Non Commercial 4.0 International (CC BY-NC 4.0)

(https://creativecommons.org/licenses/by-nc/4.0/), which permits remixing, adapting and building upon the work for non-commercial use, provided the original work is properly cited. 